\title{
The distribution of Rotavirus $G$ and $P$ genotypes in children with acute gastroenteritis in Cukurova region, Turkey
}

\author{
Fugen Yarkin ${ }^{1}$, Deniz Yildirim ${ }^{1}$, Umit Sizmaz Celik ${ }^{2}$, Hakan Demirhindi ${ }^{3}$, Fatih Koksal ${ }^{1}$ \\ Department of Microbiology, Faculty of Medicine, University of Cukurova, Adana, Turkey. \\ ${ }^{2}$ Department of Pediatrics, Obstetrics and Child Care Hospital, Adana, Turkey. \\ ${ }^{3}$ Department of Public Health, Faculty of Medicine, University of Cukurova, Adana, Turkey.
}

\begin{abstract}
Background: Rotavirus is the major cause of acute gastroenteritis in infants and young children worldwide. The aim of the study was to determine the frequency of rotavirus infection and the distribution of rotavirus $\mathrm{G}$ and $\mathrm{P}$ genotype combination among children under 5 years of age with acute gastroenteritis in Cukurova region, Turkey, between October 2009 and June 2010.

Material and Methods: The stool specimens $(n=846)$ collected from children with acute gastroenteritis were analyzed by enzyme-linked immunosorbent assay (ELISA) for group A rotavirus antigen. Semi-nested multiplex reverse transcription-polymerase chain reaction (RT-PCR) test was performed for rotavirus G and P genotyping.

Results: The rate of rotavirus infection was found to be in 144 patients $(17 \%)$. The predominant rotavirus genotype was G1P[8] (22.2\%), followed by G1P[4] (17.3\%), G2P[4] (13.8\%), G9P[4] (6.3\%), G9P[8] (4.8\%), G2P[8] (2.8\%), G1P[10] (2.1\%) and G4P[8] (1.4\%). The most common G genotype was G1 (41.7\%), followed by G2 (16.6\%), G9 (11.1\%) and G4 (1.4\%). Rotavirus P[4] genotype was identified in 37.5\%, P[8] in 31.2\% and P[10] in 2.1\% of samples. The prevalence of mixed rotavirus infections was $29.2 \%(n=42)$.

Conclusion: Although the predominant rotavirus genotypes circulating during the study period in our region are targets of current rotavirus vaccines, uncommon, non-vaccine rotavirus genotype combinations such as G1P[4] and G9P [4], which might appear to be the result of mixed rotavirus infections with high rate (29.2\%), were also detected. G1 is included in both recent rotavirus vaccines. The continuous investigation of molecular epidemiology of rotavirus infections is essential to evaluate the effectiveness of rotavirus vaccines.
\end{abstract}

Key words: Rotavirus, Gastroenteritis, Genotypes, ELISA, RT-PCR.

\section{Introduction}

Rotavirus is the most common cause of acute severe gastroenteritis in infants and young children worldwide. It is estimated that approximately 600,000 children die annually due to rotavirus gastroenteritis and more than $80 \%$ of deaths occur in developing countries. In developed countries, rotaviruses are associated with high morbidity, but low mortality and are the most frequently isolated pathogens in children hospitalized with acute gastroenteritis (1).

*Corresponding Author: Fügen Yarkın, Department of Microbiology, Faculty of Medicine, University of Çukurova, Adana 01330, Turkey. E-mail: fugeny@ yahoo.com Received: Apr 18, 2016. Accepted: Apr 21, 2016. Published Online: May 10, 2016.
The rotavirus belongs to the family Reoviridae, which is non-enveloped with an 11 segmented double-stranded RNA genome surrounded by a triple-layered icosahedral capsid: core, inner and outer capsid. Rotaviruses are divided into seven groups named from $\mathrm{A}$ to $\mathrm{G}$, according to the differences in inner capsid protein VP6. Groups A, $\mathrm{B}$, and $\mathrm{C}$ rotaviruses infect humans and animals, whereas the D-G groups infect only animals. Group A rotaviruses are the main cause of severe gastroenteritis in children worldwide $(2,3)$.

This is an Open Access article distributed under the terms of the Creative Commons Attribution Non-Commercial License (http://creativecommons.org/licenses/bync/4.0/) which permits unrestricted non-commercial use, distribution, and reproduction in any medium, provided the original work is properly cited. 
The genes encoding the outer capsid viral proteins VP7 and VP4, which are responsible for cell attachment and entry, allow the classification of group A rotaviruses into $\mathrm{G}$ and $\mathrm{P}$ genotypes, respectively. Up to now, at least $27 \mathrm{G}$ types and $35 \mathrm{P}$ types have been described for rotavirus group A, but it has been known that only $10 \mathrm{G}$ (G1-G6, G8-G10, and G12) and 11 P (P1, P3-P6, P8-P11, P14 and P19) genotypes infect humans (4). Furthermore, epidemiological studies have shown that five of the $G$ genotypes (G1, G2, G3, G4, and G9) and three of the P genotypes (P1A[8], $\mathrm{P} 1 \mathrm{~B}[4]$, and $\mathrm{P} 2 \mathrm{~A}[6])$ are globally common in humans $(1,3,5,6)$. Another issue that is of critical importance is the emergence of new reassortant virus strains in case of coinfection with different rotavirus strains. There is a large number of $G$ and $P$ genotype combinations circulating in the human population, however five major combinations of $\mathrm{G}$ and $\mathrm{P}$ genotypes worldwide are G1P[8],G2P[4], G3P[8], G4P[8], and G9P[8] $(1,5)$.

Considering the genetic diversity of rotaviruses, it is advisable to determine geographic variation of predominant strains for effective rotavirus vaccine development. At present, there are two rotavirus vaccines approved in many countries including Turkey, which are Rotarix (GlaxoSmithKline, Research Triangle Park, NC, USA), a live attenuated monovalent vaccine containing rotavirus P1A[8]G1 genotype and RotaTeq (Merck, Rahway, NJ, USA), a live attenuated pentavalent vaccine consisting of G1, G2, G3, G4, and P1A[8] types. However, rotavirus vaccines are not yet included in national immunization programme in Turkey. The efficacy of the Rotarix and RotaTeq against severe diarrhea was found to be $85 \%$ and $98 \%$, respectively (3, 7). While deciding the strategy for immunization against rotavirus, it is important to detect the regional incidence of rotavirus gastroenteritis and predominant circulating genotypes before and after immunization.

The aim of this study was to determine the frequency of rotavirus infection and the distribution of rotavirus $G$ and $\mathrm{P}$ genotypes among children under 5-years-old with acute gastroenteritis in Çukurova region, Turkey, between October 2009 and June 2010. The results of this study would provide epidemiological information before national implementation of rotavirus vaccines into routine childhood immunization schedule in Turkey.

\section{Material and methods Sample collection}

A total of 846 stool specimens were collected from unvaccinated children with acute gastroenteritis, younger 5 years of age, admitted to Adana Obstetrics and Child Care Hospital from October 2009 to June 2010. The stool samples were stored at $-80^{\circ} \mathrm{C}$ until tested. Clinical symptoms and demographic data of the patients were obtained via a questionnaire filled out by a physician by face to face interview and after physical examination of the patients.

\section{Rotavirus antigen detection}

Stool samples were tested for group A rotavirus antigen using a solid phase sandwich type enzyme immunoassay (Ridascreen rotavirus ELISA test, R-Biopharm AG, Germany). Rotavirus antigen-positive samples were evaluated for rotavirus $\mathrm{G}$ and $\mathrm{P}$ genotyping by seminested multiplex RT-PCR test using the primers previously described by Gentsch et al.,(8) Gouvea et al.,(9) and Iturriza-Gómara et al.(10).

\section{RNA extraction from stool samples}

Frozen stool samples were incubated on the bench to dissolve and then diluted 1:10 in phosphate-buffered saline. Viral RNA was extracted using the High Pure Viral RNA Kit (Roche Diagnostics, Mannheim, Germany) according to the manufacturer's instructions.

\section{$R T-P C R$ for rotavirus $G$ and $P$ typing}

The $\mathrm{G}$ and $\mathrm{P}$ genotyping of rotavirus was performed by using two-step RT-PCR. For rotavirus G genotyping, the $1062 \mathrm{bp}$ fragment of the VP7 gene was amplified with the forward primer Beg9 (5'- GGC TTT AAA AGA GAG AAT TTC CGT CTG G- 3') and the reverse primer End9 (5'-GGT CAC ATC ATA CAA TTC TAA TCT AAG-3'). For $\mathrm{P}$ genotyping, the consensus primers Con2 (5'-ATT TCG GAC CAT TTA TAA CC-3') and Con3 (5'- TGG CTT CGC CAT TTT ATA GAC A-3') were used to amplify VP4 gene fragment of the 876 bp (8-10). For $\mathrm{G}$ genotyping, the reaction was carried out with an initial reverse transcription step. Synthesis of cDNA was carried out in $20 \mu \mathrm{l}$ reaction volume by using $10 \mathrm{U}$ of reverse transcriptase enzyme (Roche Diagnostics, Mannheim, Germany), 25 pmol of each Beg9, and End9 primers, 20U RNasin (Roche, Diagnostics, Mannheim, Germany), $1 \mathrm{mM}$ dNTP mix, $4 \mu \mathrm{l}$ of $5 \mathrm{X}$ RT-buffer, deionized distilled water, and $5 \mu$ RNA extract, which 
were incubated at $55^{\circ} \mathrm{C}$ for 30 minute, followed by heating at $85^{\circ} \mathrm{C}$ for 5 minute to inactivate the enzyme.

The amplification reaction was performed with a $50 \mu 1$ reaction volume consisting of 10X PCR Taq Buffer, 1.5 $\mathrm{mM} \mathrm{MgCl} 2,200 \mu \mathrm{M}$ dNTP mix, 25 pmol of each Beg9 and End9 primers, 2 U Taq DNA polymerase (Fermentas Life Sciences), and $5 \mu \mathrm{l}$ cDNA. The thermal cycling conditions were as follows: initial denaturation at $94^{\circ} \mathrm{C}$ for 3 minutes, followed by 35 cycles of 1 minute denaturation at $94^{\circ} \mathrm{C}, 2$ minutes annealing at $42^{\circ} \mathrm{C}$, and 1 minute extension at $72^{\circ} \mathrm{C}$. The final extension step was carried out at $72^{\circ} \mathrm{C}$ for 10 minutes. PCR products were analyzed on an agarose gel stained with ethidium bromide and visualized in ultraviolet transilluminator. The same RT-PCR protocol was used for P genotyping of rotavirus with consensus primers Con2 and Con3 amplifying VP4 gene (876bp).

\section{Semi-nested multiplex PCR for rotavirus specific $G$ and P genotyping}

Rotavirus specific $\mathrm{G}$ and $\mathrm{P}$ genotyping was performed using a semi-nested type specific multiplex RT-PCR test that detects seven $\mathrm{G}$ types and six P types (8-10). Briefly, in order to identify the specific $G$ type, the amplicons obtained by consensus PCR, type specific primers (G1, G2, G3, G4, G8, G9, and G10) and consensus primer RVG9 for the VP7 gene were used in semi-nested type specific multiplex RT-PCR. For $\mathrm{P}$ genotyping, the amplicons obtained by consensus PCR, type specific primers ( $\mathrm{P} 4, \mathrm{P} 6, \mathrm{P} 8, \mathrm{P} 9, \mathrm{P} 10$, and $\mathrm{P} 11)$ and consensus primer Con3A for the VP4 gene were used (8-10). Both $G$ and $P$ genotyping protocols were identical and performed with a $50 \mu 1$ reaction volume consisting of $5 \mu 1$ of 10X PCR Taq Buffer (100 mM Tris-HCl [pH 8.8], 500 $\mathrm{mM} \mathrm{KCl}$ ), $2 \mathrm{mM} \mathrm{MgCl} 2,200 \mu \mathrm{M}$ dNTP mix, 20 pmol of each type specific primers and consensus primer, $2 \mathrm{U}$ Taq DNA polymerase (Fermentas), and $2 \mu$ product of first round PCR. The thermal cycling conditions were as follows: initial denaturation at $94^{\circ} \mathrm{C}$ for 3 minutes, followed by 35 cycles of amplification $\left(1\right.$ minute at $94^{\circ} \mathrm{C}$, 2 minutes at $42^{\circ} \mathrm{C}, 1$ minute at $72^{\circ} \mathrm{C}$ for each cycles), and a final extension of 10 minutes at $72^{\circ} \mathrm{C}$. All amplified products of $\mathrm{G}$ and $\mathrm{P}$ genotypes were examined by gel electrophoresis in $2 \%$ agarose gel.

\section{Statistical analyzes}

The dependent factor in our study was defined as "rotavirus positivity". The independent variables tested were sex, age, symptoms include diarrhea, duration of diarrhea, number of daily bowel movements, vomiting, daily number of vomiting, fever, dehydration, and hospitalization. Chi-square test $(\chi 2)$ was used for statistical comparison using EpiInfo 6.0 software. The pvalue less than 0.05 were accepted as significant with $95 \%$ of confidence.

\section{Results}

From a total of 846 stool specimens analyzed, 144 (17\%) samples were positive for rotavirus antigen. The majority of rotavirus positive cases $(71.5 \%)$ were under 12 months of age (Table 1). Rotavirus positivity was more frequently observed in age group of 6-12 months among both males $(\chi 2=15.52 ; \quad \mathrm{p}=0.00043)$ and females $(\chi 2=10.86 ; \mathrm{p}=0.0044)$, in cases with diarrhea lasting 3-4 days $(\chi 2=12.12 ; \mathrm{p}=0.00234)$, with bowel movements of between 6-10 per day $(\chi 2=17.75 ; \mathrm{p}=0.00014)$, with vomiting $(\chi 2=76.45, \mathrm{p}<0.0001)$, with vomiting frequency of 5 or more daily $(\chi 2=34.27 ; p<0.0001)$, in cases with dehydration $(\chi 2=12.93, \mathrm{p}=0.00032)$, and especially in those with severe dehydration $(\chi 2=3.14, p<0.0001)$. In addition, hospitalization was more frequently observed among the children with rotavirus positivity $(\chi 2=12.83$, $\mathrm{p}<0.001)$, and rotavirus positive children were 1.96 times more hospitalized [Odds ratio $(\mathrm{OR})=1.96$ and $95 \%$ Confidence Interval $(\mathrm{CI})=1.34-2.85]$. Rotavirus positivity was not affected by sex $(\chi 2=0.02 ; \mathrm{p}=0.877)$, fever presence $(\chi 2=0.46, \mathrm{p}=0.499$; Table 1$)$.

According to the monthly distribution of rotavirus infection in children with acute gastroenteritis throughout the study period, higher positivity was observed in December (46 cases, 31.9\%), November (25 cases, $17.3 \%)$, and January (23 cases, 16\%), respectively (Figure 1).

The most prevalent rotavirus genotypes were G1P[8] $(22.2 \%)$ and G1P[4] (17.3\%), followed by G2P[4] (13.8\%), G9P[4] (6.3\%), G9P[8] (4.8\%), G2P[8] (2.8\%), G1P[10] $(2.1 \%)$, and G4P[8] (1.4\%) in 144 rotavirus positive cases (Table 2). Among rotavirus positive samples, the most common G genotype was G1 (41.7\%), followed by G2 (16.6\%), G9 (11.1\%), and G4 (1.4\%). The most frequently isolated $\mathrm{P}$ type was $\mathrm{P}[4]$ with the rate of $37.5 \%$, followed by $\mathrm{P}[8]$ (31.2\%) and $\mathrm{P}[10]$ $(2.1 \%)$. Mixed rotavirus infections occurred in $29.2 \%$ (42) of cases (Table 3). 
Table 1. Clinical and epidemiological features of children with and without rotavirus gastroenteritis.

\begin{tabular}{|c|c|c|c|c|c|}
\hline \multirow{2}{*}{ Data } & \multicolumn{2}{|c|}{ Rotavirus positive } & \multicolumn{2}{|c|}{ Rotavirus negative } & \multirow[b]{2}{*}{$p$-value } \\
\hline & $\begin{array}{l}\text { Number } \\
(n=144)\end{array}$ & $\begin{array}{r}\% * \\
(17.0) \\
\end{array}$ & $\begin{array}{l}\text { Number } \\
(\mathrm{n}=702)\end{array}$ & $\begin{array}{c}\% * \\
(\mathbf{8 3 . 0})\end{array}$ & \\
\hline \multicolumn{5}{|l|}{ Sex } & $p>0.05$ \\
\hline Male & 79 & 54.9 & 393 & 56.0 & \\
\hline Female & 65 & 45.1 & 309 & 44.0 & \\
\hline \multicolumn{5}{|l|}{ Age groups (month) } & $p<0.01 * *$ \\
\hline $0-5$ & 41 & 28.5 & 344 & 49.0 & in both sexes \\
\hline $6-12$ & 62 & 43.0 & 175 & 24.9 & (with no \\
\hline $13-24$ & 33 & 22.9 & 68 & 9.7 & difference \\
\hline $25-36$ & 3 & 2.1 & 30 & 4.3 & between sexes \\
\hline $37-48$ & 2 & 1.4 & 22 & 3.1 & $p>0.05)$ \\
\hline $49-60$ & 3 & 2.1 & 63 & 9.0 & \\
\hline \multicolumn{6}{|l|}{ Symptoms } \\
\hline \multicolumn{6}{|l|}{$\begin{array}{l}\text { Duration of } \\
\text { diarrhea (day) }\end{array}$} \\
\hline $1-2$ & 32 & 22.0 & 196 & 28.0 & \\
\hline $3-4 * *$ & 58 & 40.0 & 182 & 26.0 & $p<0.01 * *$ \\
\hline $5-7$ & 54 & 38.0 & 324 & 46.0 & \\
\hline \multicolumn{6}{|c|}{$\begin{array}{l}\text { Number of daily } \\
\text { bowel movements }\end{array}$} \\
\hline $3-5$ & 75 & 52.1 & 489 & 69.7 & \\
\hline $6-10 * *$ & 65 & 45.1 & 206 & 29.3 & $p<0.001 * *$ \\
\hline $11-15$ & 4 & 2.8 & 7 & 1.0 & \\
\hline Vomiting & 106 & 73.6 & 238 & 33.9 & $p<0.0001 * *$ \\
\hline \multicolumn{6}{|c|}{ Daily number of vomiting } \\
\hline $1-4$ & 47 & 44.3 & 174 & 73.1 & \\
\hline $5-8 * *$ & 39 & 36.8 & 55 & 23.1 & $p<0.0001 * *$ \\
\hline $9-12 * *$ & 20 & 18.9 & 9 & 3.8 & \\
\hline Fever & 75 & 52.1 & 341 & 48.6 & $p>0.05$ \\
\hline Dehydration & 102 & 70.8 & 380 & 54.1 & $p<0.001 * *$ \\
\hline Mild & 63 & 61.8 & 319 & 84.0 & \\
\hline Moderate & 15 & 14.7 & 40 & 10.5 & \\
\hline Severe $* *$ & 24 & 23.5 & 21 & 5.5 & $p<0.0001 * *$ \\
\hline Hospitalization $* *$ & 79 & 54.8 & 269 & 38.3 & $p<0.001 * *$ \\
\hline
\end{tabular}

Table 2. Distribution of rotavirus $G$ and $P$ types.

Number of specimens $(\%)$

\begin{tabular}{lcccccccc} 
Genotype & $\mathbf{P}[\mathbf{4}]$ & $\mathbf{P}[\mathbf{8}]$ & $\mathbf{P}[\mathbf{4}]+\mathbf{P}[\mathbf{8}]$ & $\mathbf{P}[\mathbf{1 0}]$ & $\mathbf{P}[\mathbf{4}]+\mathbf{P}[\mathbf{1 0}]$ & $\mathbf{P}[\mathbf{8}]+\mathbf{P}[\mathbf{1 0}]$ & $\mathbf{P}[\mathbf{4}]+\mathbf{P}[\mathbf{1 1}]$ & Total \\
\hline G1 & $25(17.3)$ & $32(22.2)$ & $23(16.0)$ & $3(2.1)$ & - & - & $2(1.4)$ & $85(59.0)$ \\
G2 & $20(13.8)$ & $4(2.8)$ & $2(1.4)$ & - & - & - & - & $26(18.0)$ \\
G9 & $9(6.3)$ & $7(4.8)$ & $2(1.4)$ & - & $2(1.4)$ & - & $1(0.7)$ & $21(14.6)$ \\
G4 & - & $2(1.4)$ & - & - & - & - & - & $2(1.4)$ \\
G1+G9 & $3(2.1)$ & - & $2(1.4)$ & $2(1.4)$ & $1(0.7)$ & $1(0.7)$ & - & $9(6.3)$ \\
G2+G10 & $1(0.7)$ & - & - & - & - & - & - & $1(0.7)$
\end{tabular}

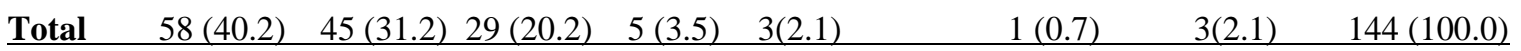




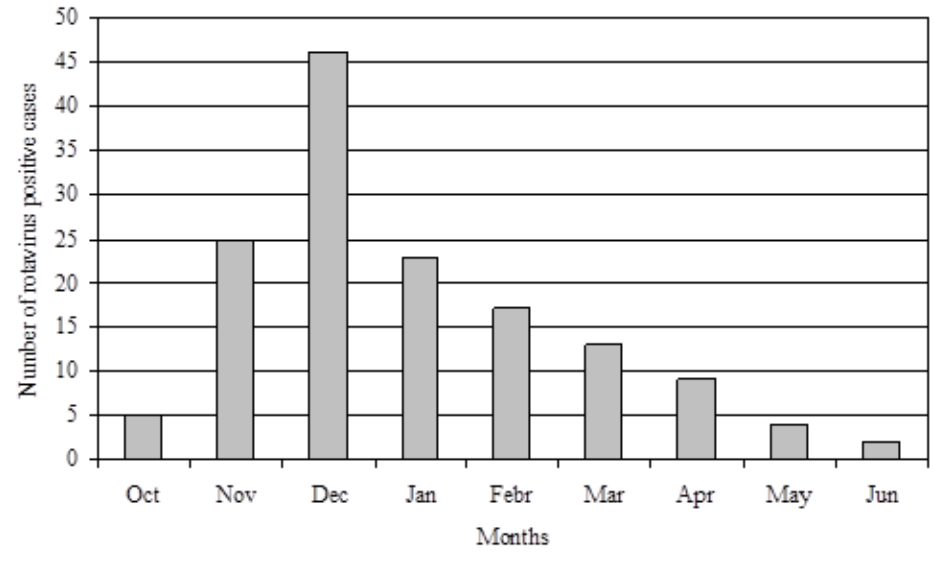

Figure 1. Monthly distribution of rotavirus positive and negative gastroenteritis cases.
Table 3. Distribution of rotavirus G-P genotype combinations of mixed infections.

\begin{tabular}{lrc}
\hline & \multicolumn{2}{c}{ Mixed infections } \\
\hline $\begin{array}{l}\text { Genotype } \\
\text { combinations }\end{array}$ & Number & $\%$ \\
G1/P[4]P[8] & 23 & 16 \\
G1+G9/P[4] & 3 & 2.1 \\
G2/P[4]P[8] & 2 & 1.4 \\
G9/P[4]P[8] & 2 & 1.4 \\
G1+G9/P[10] & 2 & 1.4 \\
G1+G9/P[4]P[8] & 2 & 1.4 \\
G1/P[4]P[11] & 2 & 1.4 \\
G9/P[4]P[10] & 2 & 1.4 \\
G9/P[4]P[11] & 1 & 0.7 \\
G2+G10/P[4] & 1 & 0.7 \\
G1+G9/P[4]P[10] & 1 & 0.7 \\
G1+G9/P[8]P[10] & 1 & 0.7 \\
Total & 42 & 29.2 \\
\hline
\end{tabular}

rotavirus infection in our study was $17 \%$ (144 cases). The rates of rotavirus gastroenteritis are comparable in both developed and developing countries, but mortality from diarrhea is greater in developing countries as a result of inadequate treatment $(1,2)$.

In our study, the most common rotavirus $\mathrm{G}$ genotype was G1 with the rate of $41.7 \%$, followed by G2 (16.6\%), G9 $(11.1 \%)$, and G4 (1.4\%). The genotype G3, which is also one of the most common types worldwide, was not identified during the study period. Interestingly, the predominant $\mathrm{P}$ genotype was $\mathrm{P}$ [4] (37.5\%), but not P[8] $(31.2 \%)$. There is limited number of studies conducted on the distribution of rotavirus genotypes in Turkey. Reports in different years from Ankara (24) and Izmir (25) regions in Turkey also showed that G1 was the dominant genotype with $86 \%$ and $75.1 \%$, respectively, but being higher than our finding that of $41.7 \%$. We found G2 genotype as the second most common (16.6\%) type, was higher than the rates of $3.3 \%$ and $0.8 \%$ reported in Ankara and Izmir, respectively $(24,25)$. Higher frequency of G1 genotype has also been consistent with previous results for rotavirus infection in France (61.7\%) and Japan $(72.7 \%)(27,19)$. Our finding of $41.7 \%$ rate for G1 type was similar to that reported from Italy in 2008 (G1 40.7\%), however the second most common type observed in Italy was G9, but not G2 (28). 
The most prevalent genotype combination in our study was G1P[8] (22.2\%) which was also identified as predominant genotype in the previous studies (14,28-30). The other genotypes were found to be G1P[4] (17.3\%), G2P[4] (13.8\%), G9P[4] (6.3\%), G9P[8] (4.8\%), G2P[8] (2.8\%), G1P[10] (2.1\%), and G4P[8] (1.4\%), respectively. In contrast with these findings, Çataloluk et al. reported the genotype G4P[8] as the predominant type $(42.2 \%)$ and G1P[8] as the second most common genotype $(26.6 \%)$ circulating in Gaziantep region of Turkey in 2005 (31). However, another study indicated that G3P[8] (38.9\%) was the most frequent genotype in Ankara from April 2009 to February 2010 (32). As distinct from the other studies $(30,33)$, the combinations of $\mathrm{G}$ genotypes with $\mathrm{P}[4]$ represented relatively high frequencies of G1P[4] (17.3\%), G2P[4] (13.8\%), and G9P[4] (6.3\%) in our study. The rates for G1P[4], G2P[4], and G9P[4] genotypes in Europe were 0.29\%, $10 \%$ and $0.19 \%$ respectively (30). The frequency of G9P[8] was $4.8 \%$ in our region. Whereas, G9P[8] was detected to be the most common type of rotavirusassociated gastroenteritis in Poland $(71.1 \%)$ and Spain (87.7\%) (14). G9P[8] was reported as the second most common genotype $(10.1 \%)$ in Istanbul, Turkey (29). Our finding of G2P[8] was $2.8 \%$, while Ittiruza et al. found $\mathrm{G} 2 \mathrm{P}[8]$ as $0.47 \%$ in Europe (30). The presence of genotype G1P[10] (2.1\%), which might be due to possible reassortment between human and animal rotavirus strains, was reported in our study for the first time in Turkey. This genotype was observed in Europe with 1.7\%.30 The globally common G1P[8], G2P[4], G4P[8], and G9P[8] genotypes constituted $42.7 \%$ of rotavirus strains, but G3P[8], which is also another common genotype, was not detected in our study. The percentage of mixed rotavirus infection in the present study was quite high (29.2\%) compared to those reported in previous studies (28-31). These findings confirm that rotavirus genotype distribution varies between regions, countries, and also differs from year to year.

\section{Conclusion}

In conclusion, although the predominant rotavirus genotypes circulating during the study period in our region are the targets of current rotavirus vaccines, uncommon, non-vaccine rotavirus genotype combinations such as G1P[4] (17.3\%) and G9[4] (6.3\%) were also detected. The high rate of mixed rotavirus infections (29.2\%) in the study population might increase emergence of new strains due to natural reassortment, which might decrease the effectiveness of current rotavirus vaccines against rotavirus infections. Therefore, continuous prospective monitoring of circulating strains of rotavirus is essential to evaluate the efficacy and convenience of rotavirus vaccines.

\section{Ethics Committee Approval: N.A. \\ Informed Consent: N.A.}

Peer-review: Externally peer-reviewed.

Conflict of Interest: No conflict of interest was declared by the authors.

Financial Disclosure: This project was funded by The Scientific and Technological Research Council of Turkey (TUBITAK), Project code: 109S205.

\section{References}

1. Bernstein DI. Rotavirus overview. Pediatr Infect Dis J 2009; 28: 50-53.

2. Gray J, Vesikari T, Van Damme P, Giaquinto C, Mrukowicz J, Guarino A, et al. Rotavirus. J Pediatr Gastroenterol Nutr 2008; 46: 24-31.

3. Dennehy PH. Rotavirus vaccines: an overview. Clin Microbiol Rev 2009; 21: 198-208.

4. Matthijnssens J, Ciarlet M, McDonald SM, Attoui H, Bányai $\mathrm{K}$, Brister JR, et al. Uniformity of rotavirus strain nomenclature proposed by the Rotavirus Classification Working Group (RCWG). Arch Virol 2011; 156: 1397-1413.

5. O'ryan M. The ever-changing landscape of rotavirus serotypes. Pediatr Infect Dis J 2009; 28: 60-62.

6. Tate JE, Patel MM, Steele AD, Gentsch JR, Payne DC, Cortese MM, et al. Global impact of rotavirus vaccines. Expert Rev Vaccines 2010; 9: 395-407.

7. Desselerger U, Manktelow E, Li W, Cheung W, IturrizaGómara M, Gray J. Rotaviruses and rotavirus vaccines. British Med Bull 2009; 90: 37-51.

8. Gentsch JR, Glass RI, Woods P, Gouvea V, Gorziglia M, Flores $\mathrm{J}$, et al. Identification of group A rotavirus gene 4 types by polymerase chain reaction. J Clin Microbiol 1992; 30: 1365-1373.

9. Gouvea V, Glass RI, Woods P, Taniguchi K, Clark HF, Forrester B, et al. Polymerase chain reaction amplification and typing of rotavirus nucleic acid from stool specimens. J Clin Microbiol 1990; 28: 276-282.

10. Iturriza-Gómara M, Kang G, Gray J. Rotavirus genotyping: keeping up with an evolving population of human rotaviruses. J Clin Virol 2004; 31: 259-265.

11. Ruiz-Palacios GM, Pérez-Schael I, Velázquez FR, Abate H, Breuer T, Clemens SC, et al.; Human Rotavirus Vaccine Study Group. Safety and efficacy of an attenuated vaccine against severe rotavirus gastroenteritis. $N$ Engl J Med 2006; 354: 11-22.

12. Correia JB, Patel MM, Nakagomi O, Montenegro FM, Germano EM, Correia NB, et al. Effectiveness of monovalent rotavirus vaccine (Rotarix) against severe diarrhea caused by serotypically unrelated G2P[4] strains in Brazil. J Infect Dis 2010; 201: 363-369.

13. Vesikari T, Karvonen A, Prymula R, Schuster V, Tejedor JC, Cohen R, et al. Efficacy of human rotavirus vaccine against rotavirus gastroenteritis during the first 2 years of life in 
European infants: randomized, double-blind controlled study. Lancet 2007; 370: 1757-1763.

14. Diez-Domingo J, Baldo JM, Patrzalek M, Pazdiora P, Forster J, Cantarutti L, et al.; the SPRIK Rotavirus Study Group. Primary care-based surveillance to estimate the burden of rotavirus gastroenteritis among children aged less than 5 years in six European countries. Eur J Pediatr 2011; 170: 213222.

15. Giaquinto C, van Damme P; REVEAL Study Group. Age distribution of paediatric rotavirus gastroenteritis cases in Europe: the REVEAL study. Scand J Infect Dis 2010; 42: 142147.

16. Lyman WH, Walsh JF, Kotch JB, Weber DJ, Gunn E, Vinjé J. Prospective study of etiologic agents of acute gastroenteritis outbreaks in child care centers. $J$ Pediatr 2009; 154: 253-257.

17. Mast TC, Walter EB, Bulotsky M, Khawaja SS, DiStefano DJ, Sandquist MK, et al. Burden of childhood rotavirus disease on health systems in the United States. Pediatr Infect Dis J 2010; 29: 19-25.

18. Waggie Z, Hawkridge A, Hussey GD. Review of rotavirus studies in Africa: 1976-2006. J Infect Dis 2010; 202: 23-33.

19. Phan TG, Khamrin P, Quang TD, Dey SK, Takanashi S, Okitsu S, et al. Detection and genetic characterization of group A rotavirus strains circulating among children with acute gastroenteritis in Japan. J Virol 2007; 81: 4645-4653.

20. Yang J, Wang T, Wang Y, Lu B, Bai X, Zhang L, et al. Emergence of human rotavirus group a genotype $\mathrm{G} 9$ strains, Wuhan, China. Emerg Infect Dis 2007; 13: 1587-1589.

21. Li DD, Liu N, Yu JM, Zhang Q, Cui SX, Zhang DL, et al. Molecular epidemiology of G9 rotavirus strains in children with diarrhea hospitalized in Mainland China from January 2006 to December 2007. Vaccine 2009; 27: 40-45.

22. Ramani S, Kang G. Burden of disease \& molecular epidemiology of group A rotavirus infections in India. Indian J Med Res 2007; 125: 619-632.

23. Altındiş M, Beştepe G, Çeri A, Yavru S, Kalaycı R. Frequency of rotavirus and enteric adenovirus infection in children with acute gastroenteritis. Med J Süleyman Demirel Univ 2008; 15: 17-20.

24. Şimşek Y, Bostancı I, Bozdayı G, Öner N, Kamruddin A, Rota S, et al. Frequency and serotype features of rotavirus in 05 age children with acute gastroenteritis. Turkiye Klinikleri J Pediatr 2007; 16: 165-170.

25. Kurugöl Z, Geylani S, Karaca Y, Umay F, Erensoy S, Vardar F, et al. Rotavirus gastroenteritis among children under five years of age in Izmir, Turkey. Turk J Pediatr 2003; 45: 290-294.

26. Çiçek C, Karataş T, Altuğlu I, Koturoğlu G, Kurugöl Z, Bilgiç A. Comparison of ELISA with shell vial cell culture method for the detection of human rotavirus in stool specimens. New Microbiol 2007; 30: 113-118.

27. De Rougemont A, Kaplon J, Pillet S, Mory O, Gagneur A, Minoui-Tran A, et al.; the French Rotavirus Network. Molecular and clinical characterization of rotavirus from diarrheal infants admitted to pediatric emergency units in France. Pediatr Infect Dis J 2011; 30: 118-124.

28. Zucotti G, Meneghin F, Dilillo D, Romanò L, Bottone R, Mantegazza C, et al. Epidemiological and clinical features of rotavirus among children younger than 5 years of age hospitalized with acute gastroenteritis in Northern Italy. $B M C$ Infect Dis 2010; 10: 218.
29. Bozdayı G, Dogan B, Dalgic B, Bostanci I, Sari S, Battaloglu NO, et al. Diversity of human rotavirus G9 among children in Turkey. J Med Virol 2008; 80: 733-740.

30. Iturriza-Gomara $M$, Dallman $T$, Bányai $K$, Böttiger $B$, Buesa J, Diedrich S, et al. Rotavirus genotypes co-circulating in Europe between 2006 and 2009 as determined by EuroRotaNet, a pan-European collaborative strain surveillance network. Epidemiol Infect 2010; 16: 1-15.

31. Çataloluk O, Itturriza M, Gray J. Molecular characterization of rotaviruses circulating in the population in Turkey. Epidemiol Infect 2005; 133: 673-678.

32. Meral M, Bozdayı G, Özkan S, Dalgıç B, Alp G, Ahmed K. Rotavirus prevalence in children with acute gastroenteritis and the distribution of serotypes and electropherotypes. Mikrobiyol Bul 2011; 45: 104-112.

33. Tcheremenskaia O, Marucci G, De Petris S, Ruggeri FM, Dovecar D, Sternak SL, et al.; Rotavirus Study Group. Molecular epidemiology of rotavirus in Central and Southeastern Europe. J Clin Microbiol 2007; 45: 2197-2204.

\section{How to cite?}

Yarkın F, Yıldırım D, Çelik ÜS, Demirhindi H, Köksal F. The distribution of rotavirus $\mathrm{G}$ and $\mathrm{P}$ genotypes in children with acute gastroenteritis in Çukurova region, Turkey. J Immunol Clin Microbiol 2016; 1(1): 3-9

DOI: http://dx.doi.org/10.5455/jicm.7.20160520

Submit your next manuscript to the JICM and take full advantage of:

- Convenient online submission,

- Thorough peer review, Fast Response,

- No charges,

- Immediate publication on acceptance,

- Inclusion in Scopemed, Goggle Scholar and High quality indexes,

- Research which is freely available for redistribution of the worldwide literature.

To submit your manuscript, click on http://www.jiacm.com

Published by The QMEL.org

International Medical Education Library

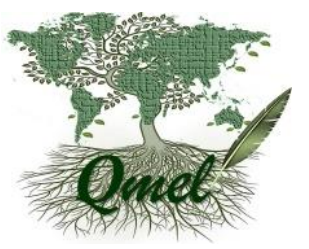

